\title{
Transient behavior of ASTRID with a gas power conversion system
}

\author{
F. Bertrand ${ }^{1}$, G. Mauger, M. Bensalah, P. Gauthé \\ CEA, DEN, DER, F-13108, Saint Paul-lez-Durance, France
}

\section{Keywords}

SFR, ASTRID, transient analysis, gas PCS, loss of off-site power, depressurization, system regulation

\begin{abstract}
The present article is dedicated to preliminary transient studies carried out for the analysis of the system overall behavior of the ASTRID (Advanced Sodium Technological Reactor for Industrial Demonstration) demonstrator developed in France by CEA and its industrial partners. ASTRID is foreseen to demonstrate the progress made in SFR technology at an industrial scale by qualifying innovative options, some of which still remain open in the areas requiring improvements, especially safety and operability. Among the innovative options, a gas power conversion systems (PCS) is envisaged. In this latter innovative PCS, the working gas is nitrogen whose flow rate delivers power to a turbine driving with the same shaft two compressors (low and high pressure) separated by an intercooler. The other part of the work delivered by the gas is used to drive the alternator that produces electricity. The main objective of such a PCS consists in avoiding physically the possibility of a sodium/water reaction with the secondary circuit but the impact of this PCS on the control of the accidents has also been studied. The main purpose of the studies presented in the paper is to assess the dynamic behavior of ASTRID including a gas PCS with the CATHARE2 code. The first transient presented deals with a loss of off-site power and has been calculated for the gas PCS but also for a classical steam/water PCS for comparison purpose. Then typical transients of gas system have been investigated. Several families of initiating events affecting the PCS are studied: breaches in the ternary circuit, a loss of power supply, a loss of main heat sink and the spurious
\end{abstract}


opening of the turbine by-pass valve. Regarding this last transient, sensitivity studies have shown that an adequate design of the turbomachine by-pass lines allows a control of the event without shutdown. Moreover, regulating actions following the scram are also investigated in order to take benefit of the PCS in order to remove the decay heat.

\section{Introduction}

After a brief presentation of the ASTRID reactor main design options, the stress is put on the presentation of the power conversion system (PCS). In this gas innovative PCS designed by ALSTOM, the working gas is nitrogen whose flow rate delivers power to a turbine driving with the same shaft two compressors (low and high pressure) separated by an intercooler. The other part of the work delivered by the gas is used to drive the alternator that produces electricity. Moreover, a recuperator enables to preheat the gas flow entering the gas/sodium heat exchanger with the gas exhausting from the turbine. The main objective of such a PCS consists in physically avoiding the possibility of a sodium/water reaction at the interface between the secondary and the ternary circuit. In the following part of the paper, the main features of the CATHARE2 modelling of nitrogen cycle currently envisaged for ASTRID are detailed as well as the system actions simulated in the CATHARE2 input deck for transient calculations. Finally, the calculation results are presented and the consequences on the reactor (thermal shock, long term behaviour and heat removal process) of the various transients simulated are assessed. First, the seam/water and gas PCS's are compared in case of LOOP. Then the behaviour of ASTRID with a gas PCS is presented for typical transients of gas circuits.

\section{Overview of ASTRID design}

ASTRID, standing for Advanced Sodium Technological Reactor for Industrial Demonstration consists in a 1500 MWth SFR pool type reactor of about 600 MWe that is an integrated technological demonstrator designed for industrial-scale demonstration of $4^{\text {th }}$ generation sodium-cooled fast reactor (SFR) safety and operation (Le Coz et al., 2013). The main objective of ASTRID is to test advances on an industrial scale 
in dedicated areas (in particular safety, operability and in service inspection and repair). ASTRID will also be designed to perform waste transmutation in order to demonstrate the industrial feasibility of this technique for reducing volume of end waste and lifetime of ultimate waste. Additionally, ASTRID is being designed to fulfil the GENIV criteria in terms of safety, sustainability, economy and proliferation (Chenaud at al., 2013). Various innovative options have been investigated during the first stage of the conceptual design carried out in 2011 and 2012 in order to improve safety on the following points:

- prevention of core degradation and mitigation of its effects (innovative $\mathrm{CFV}^{2}$ core design with a low total voiding effect has been retained);

- elimination of the possibility of sodium/water reaction at the interface between secondary loops and ternary circuit (gas PCS whose transient behaviour is presented in this paper);

- enhancement of the reliability of the DHR systems.

\subsection{Core design}

The so-called CFV concept (version 1) featured by a low global Na voiding effect has been designed by CEA in order to increase the margin up to sodium boiling in case of unprotected transient (Chenaud et al., 2013) and also to reduce the severity of a primary power excursion should it occur in case of a severe accident (Lemasson et al., 2013; Bertrand at al., 2016). This core is an axial heterogeneous core (Fig. 1). The low voiding effect of this core results mainly from the presence of a sodium plenum above the upper fissile zone (Sciora et al., 2011) combined to the presence of a fertile plate in the inner zone of the core (Fig. 1). The height of the outer fissile zone enables the void reactivity effect to be lowered as well. All these effects lead to a reactivity decrease when the upper part of the core experiences a sodium thermal expansion or sodium boiling. Finally the overall voiding effect for this version of the core is equal to $-0,5 \$$ (one Dollar being the delayed neutron fraction).

\footnotetext{
${ }^{2} \mathrm{CFV}$ stands for « cœur à faible effet de vidange » that means core with low sodium worth effect.
} 


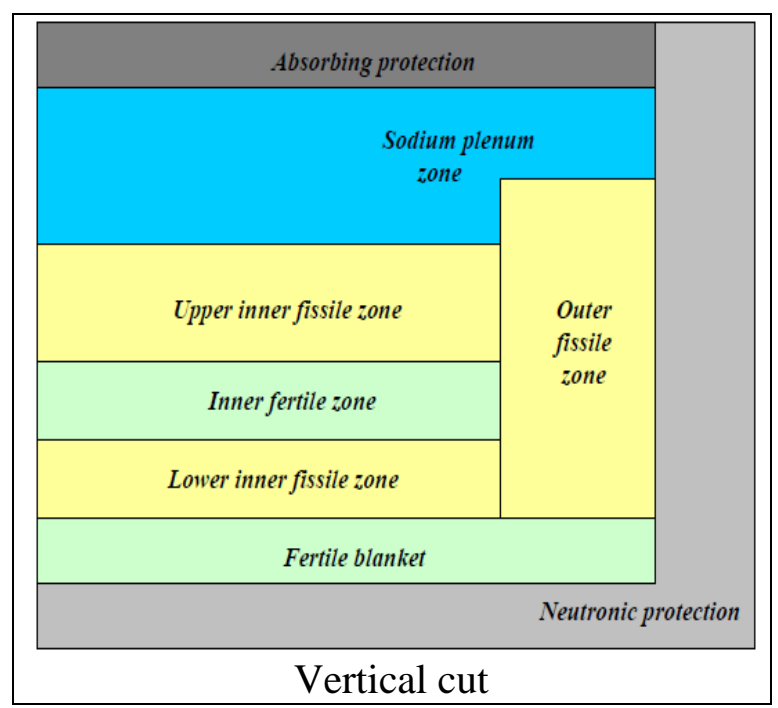

Fig 1. General CFV core geometry

\subsection{Primary and secondary systems overview}

The ASTRID pool type primary circuit includes 3 primary pumps and 4 intermediate heat exchangers (IHX) immersed in the reactor vessel (Fig. 2). Each of the 4 secondary loops delivers a fourth of the core power (375 MWth) to 3 modular steam generators (SG) or to 3 modular sodium/gas heat exchangers (SGHX); the modularity enables the impact of an event in a SG or SGHX to be reduced (Le Coz, 2013). Finally for both options, an argon covered expansion vessel is foreseen in order to protect the loop against an accidental pressure wave. The main features of the reactor operating point are provided in Table 1 for the primary and secondary circuits. The operating point is the same for both PCS options except for the ternary side.

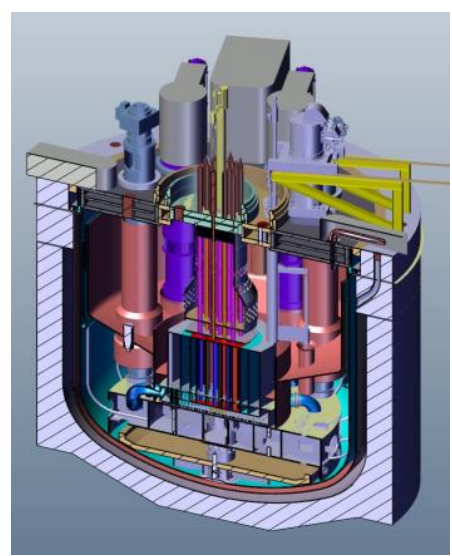

Fig. 2. Primary system arrangement for ASTRID 
Tab 1. Nominal operating point of the secondary and primary circuits

\begin{tabular}{|l|c|}
\hline \multicolumn{2}{|c|}{ Primary Circuit } \\
\hline Core flow rate $(\mathrm{kg} / \mathrm{s})$ & 7900 \\
\hline Fraction of the flow for vessel cooling $(\mathrm{kg} / \mathrm{s})$ & 600 \\
\hline Primary flow rate $(\mathrm{kg} / \mathrm{s})$ & 8500 \\
\hline Core inlet/outlet temperature $\left({ }^{\circ} \mathrm{C}\right)$ & $400 / 550$ \\
\hline Core inlet/outlet pressure $(\mathrm{bar})$ & $4.5 / 1.9$ \\
\hline \multicolumn{2}{|c|}{ Secondary Circuit } \\
\hline Secondary flow rate $(\mathrm{kg} / \mathrm{s}) \quad$ & 6370 \\
\hline IHX inlet/outlet temperature $\left({ }^{\circ} \mathrm{C}\right)$ & $345 / 530$ \\
\hline Pump inlet/outlet pressure $(\mathrm{bar})$ & $1.9 / 7.1$ \\
\hline
\end{tabular}

\subsection{Power conversion system (PCS)}

\subsection{1. $\quad$ Steam/water PCS}

The steam/water PCS option classically includes steam modular SGs (three by secondary loop), a steam turbine delivering the reactor power to an alternator, a condenser and finally a feed-water pump. Considering the operating point and the ternary flow rate (about $680 \mathrm{~kg} / \mathrm{s}$ ), the efficiency of the reactor with the steam PCS would be about $41 \%$ according to first assessments.

\subsubsection{Gas PCS}

The gas PCS using nitrogen as a working gas is presented on Figure 3 with its associated operating point (laffont et al., 2013; Cachon et al., 2012). The choice of the PCS gas has been performed by taking into account heat transfer, compression work, pressure level and its simplicity of operation. Consideration of all these criteria led to the nitrogen at 180 bars (turbine inlet) as the reference coolant. A Brayton cycle, which has never been implemented in any sodium reactor but has been investigated for High Temperature Reactors (HTR) has been chosen. This kind of cycle provides the best efficiency. The PCS flow rate is about $7160 \mathrm{~kg} / \mathrm{s}$ and a by-pass line (preliminarily located in red in Fig. 3) enables to stop or to regulate the TM speed by reducing the outlet/inlet pressure ratio, the by-pass opening consisting in an aerodynamic brake. Basically, the PCS includes a turbine driving two compressors mounted on the same shaft ${ }^{3}$. Since

\footnotetext{
${ }^{3}$ Actually, in order to better balance the forces on the shaft, a double-body turbine is now used in order to reduce the
} 
the realization of the calculations presented in the present paper, the design of the PCS has evolved and is made now of two shaft-lines, each one including two symmetric turbines arranged in parallel, a low pressure compressor and a high pressure compressor plus an alternator. The efficiency of the whole gas compression is improved by means of a pre-cooler and an intercooler separating the 2 compression stages; these heat exchangers (HX) are cooled by the heat sink of the reactor. Finally, a so-called recuperator HX permits to pre-heat the gas flow before entering the SGHX and to cool it before entering the pre-cooler. The net efficiency of the reactor considering this PCS option would be about $37.5 \%$ according to preliminary assessments (laffont et al., 2013). A multiple pipe design in parallel has been adopted in order to limit the gas velocity in the pipes (minimization of pressure drop) and in the same time to limit the maximum pipe diameter at about $1 \mathrm{~m}$ for mechanical and manufacturing reasons. A sensitivity study on the cycle parameters has shown that the turbomachine performance and the pressure losses are the most influent parameters in terms of efficiency. The main operating parameters of the PCS are presented in Table 2 .

Tab. 2. Main features of the PCS operating point

\begin{tabular}{|c|c|}
\hline Generator power & $580 \mathrm{MWe}$ \\
\hline Pre-cooler power & $570 \mathrm{MWth}$ \\
\hline Intercooler power & $340 \mathrm{MWth}$ \\
\hline Ternary flow rate & $7170 \mathrm{~kg} / \mathrm{s}$ \\
\hline Inlet temperature of SGHX & $330^{\circ} \mathrm{C}$ \\
\hline outlet temperature of SGHX & $515^{\circ} \mathrm{C}$ \\
\hline Turbine pressure (inlet/outlet) & $180 \mathrm{bar} / 73 \mathrm{bar}$ \\
\hline Low pressure compressor (inlet/outlet) & $72 \mathrm{bar} / 112 \mathrm{bar}$ \\
\hline High pressure compressor (inlet/outlet) & $111 \mathrm{bar} / 181 \mathrm{bar}$ \\
\hline
\end{tabular}

thrust on it. However, a simple line turbine is modelled in this version of the CATHARE2 input deck. 


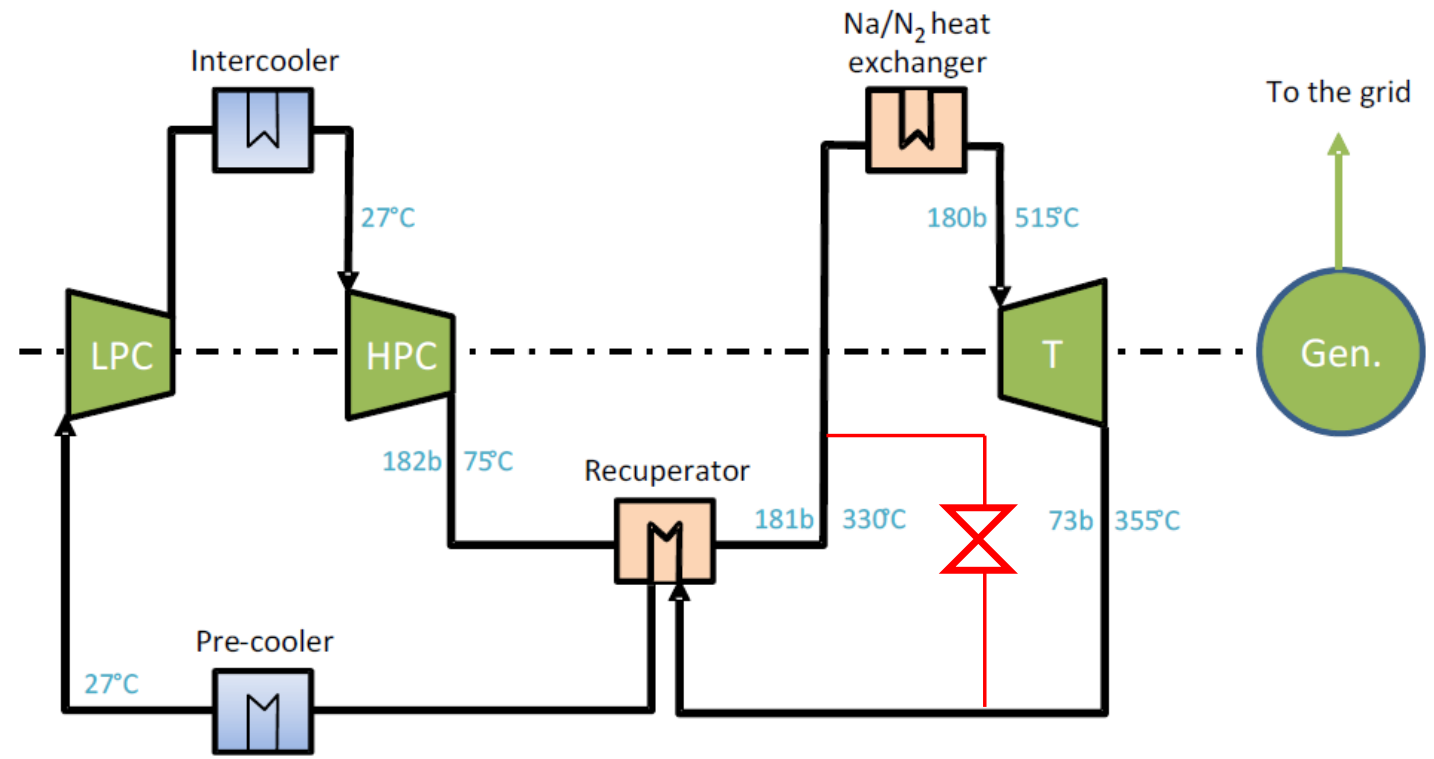

Fig. 3. Sketch of the gas PCS

(LPC: low pressure compressor; HPC: high pressure compressor; T: turbine; Gen: generator)

\section{Brief presentation of the CATHARE2 modelling of the system}

\subsection{Primary and secondary circuits}

The whole system has been modelled partly by CEA and partly by AREVA and the calculations have been run with CATHARE2 v25_3 mod2.1 (Geffraye et al., 2009). The CATHARE2 code is a 6-equations thermalhydraulic system code. Properties of sodium have been implemented in the code but the form of the friction and heat transfer correlations are the same as in the water standard version. The following neutronic effects are modelled: Doppler, sodium density, cladding expansion, fuel expansion, hexcan (HC) expansion, diagrid expansion and finally the reactivity feedback resulting from relative location of control rods within the core. All these reactivity coefficients are included in the point kinetics of neutron physics of CATHARE2 including 8 groups of delayed neutrons and 4 groups of fission products. The core channels, the IHX, the fraction of the primary flow cooling the vessel and the inlet/outlet region of the pumps are modelled thanks to 1-D CATHARE2 axial elements. The flow distribution within the cold and hot collectors is modelled thanks to a dedicated volume decomposition in several volumes whose flow-path has been assessed with CFD calculations performed in nominal regime. The secondary circuit 
is modelled with a single loop representing the 4 loops, connected to the primary system by means of a single IHX representing the 4 IHXs. A secondary pump is modelled and enables the loss and variation of flow to be simulated.

\subsection{Nitrogen PCS}

The PCS system is fully modelled in the CATHARE2 input deck as represented on Figure 4. This modelling includes a comprehensive TM module whose performance maps are derived from CEA gas fast reactor (GFR2400) performance maps (Widlund at al., 2005) but adapted to a nitrogen circuit. The parameters of the heat transfer correlation (Dittus-Boelter form) for plate type $\mathrm{Na} /$ gas exchangers used in CATHARE2 have been derived from CFD calculations. The next step of modelling will be to include the performance maps elaborated by ALSTOM in order to have a more realistic design and its associated modelling. The SGHX modules are associated to a weight equal to 12 and the recuperator to a weight of 18 in order to cope with the pre-design of the PCS. The pre-cooler and intercooled are respectively divided in 72 and 60 modules represented by a single HX in CATHARE2 associated to their weight. The whole nitrogen inventory of the circuit is around 560 tons. The rotating mass equation is solved on the TM shaft including the turbine, the compressors and the resisting torque of the alternator. 


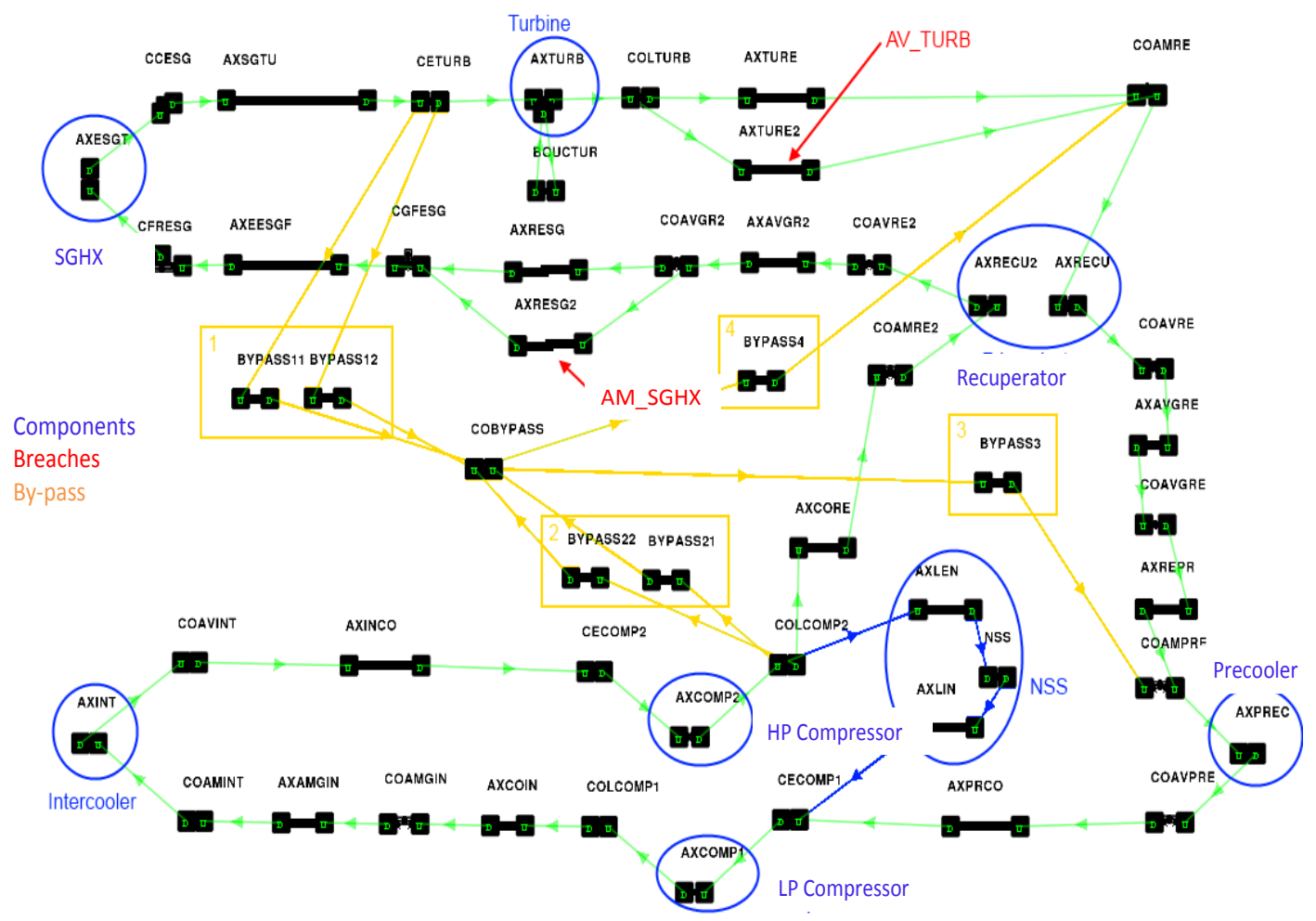

Fig. 4. Sketch of the CATHARE2 modelling of the PCS

(SGHX: sodium/gas heat exchanger, NSS: Nitrogen Supply System)

\section{System actions and regulations adopted for transient calculations}

This section is devoted to the transient analysis of ASTRID equipped with a gas PCS. In a first general part, the system actions are presented (actions triggered via the input deck after the transient initiation) and further on, the analysis of the reactor behaviour when facing specific transients of the gas PCS are presented. Additionally, the capability to remove decay heat from the system with the gas PCS is also preliminarily investigated. Finally a sensitivity study to the design of the TM by-pass line is also provided, the aim of this design alternative being to improve the capability of the reactor to withstand the transient without scram.

\subsection{Reactor trip system modelling and other system actions}

The transient input deck includes several trip parameters enabling the reactor scram to be actuated and the PCS to be protected (Table 3). Moreover, in case of reactor trip, the rotation speed of the primary pumps 
is decreased to $25 \%$ of its nominal value in 30 s and the rotation speed of the secondary pumps is reduced to $15 \%$ of its nominal value in $9 \mathrm{~s}$.

Table 3. Reactor trip parameters and ternary system protection actions

\begin{tabular}{|c|c|c|}
\hline Parameter & Threshold & Action \\
\hline Core power $(\mathrm{P})$ & $\mathrm{P} / \mathrm{P}_{\mathrm{N}}>1.08$ & Scram \\
\hline Core power/Flow rate $(\mathrm{P} / \mathrm{Q})$ & $(\mathrm{P} / \mathrm{Q}) /\left(\mathrm{P}_{\mathrm{N}} / \mathrm{Q}_{\mathrm{N}}\right)>1.35$ & Scram \\
\hline Core outlet temperature, $\mathrm{T}_{\mathrm{CO}}\left({ }^{\circ} \mathrm{C}\right)$ & $\mathrm{TcO}>583$ & Scram \\
\hline Core inlet temperature, $\left.\mathrm{T}_{\mathrm{Cl}}{ }^{\circ} \mathrm{C}\right)$ & $\mathrm{Tci}>420$ & Scram \\
\hline Core Delta T ratio & $(\mathrm{Tco}-\mathrm{Tci}) /\left(\mathrm{TcO}_{\mathrm{N}}-\mathrm{Tci}_{\mathrm{N}}\right)>1.09$ & Scram \\
\hline Alternator electrical power ratio & $\mathrm{Pelec} / \mathrm{Pelec}_{\mathrm{N}}>1.15$ & Alternator disconnection \\
\hline Alternator electrical power ratio & $\mathrm{Pelec} / \mathrm{Pelec}_{\mathrm{N}}<0.1$ & Alternator disconnection \\
\hline Turbomachinery speed $(\omega)$ & $\omega / \omega_{\mathrm{N}}>1.1$ & By-pass opening, scram \\
\hline
\end{tabular}

\subsection{System regulation}

Several regulation actions are implemented in the input deck in order to be able to remove the decay heat and to maintain all the circuit in acceptable conditions. In the frame of those exploratory studies, some regulations have been settled in order to control the power extracted by the ternary circuit (Table 4).

Table 4: regulation system in order to control the power extracted by the ternary circuit (the regulations implemented depend on the calculated transient)

\begin{tabular}{|c|c|c|}
\hline Variable to regulate & Targeted value & Action \\
\hline Cooler flow rate & $20 \%$ of $\mathrm{Q}_{\mathrm{N}}$ & Boundary condition \\
\hline Turbomachine speed & $3000 \mathrm{rpm}$ & $\begin{array}{c}\text { By-pass valve } \\
\text { opening }\end{array}$ \\
\hline $\begin{array}{c}\text { Turbomachine } \\
\text { pressure inlet }\end{array}$ & 12 bars & $\begin{array}{c}\text { Surge valve of NSS } \\
\text { opening }\end{array}$ \\
\hline
\end{tabular}

\section{Pressurized PCS transients}

The transient investigated in this paper have been distinguished between transients with PCS under pressure and PCS depressurized, those latter occurring in case of breaches. Among the pressurized transients, the black-out transient, the loss of off-site power (LOOP) and the spurious opening of by-pass valves of the TM have been simulated, including a comparison between steam/water and gas PCS. The dedicated DHR loops plugged on the primary circuit of the reactor are not used during the transient but the TM speed is kept as long as possible at $3000 \mathrm{rpm}$ by means of a regulated opening of its by-pass valve (Tab. 4). 


\subsection{LOOP (Loss Of Off-site Power)}

\subsubsection{Comparison of the reactor behaviour depending on the nature of the PCS}

As far as the gas PCS is concerned, the initiating event (IE) causing this transient is featured by the alternator disconnection and the instantaneous shutdown of the cooling flow rate on the cold side of the pre-cooler and of the intercooler. Regarding the steam/water PCS, the transient consists in a decrease up to a residual value of the flow rate of feed water of the SG in 30 seconds. The actions triggered by the LOOP on the primary and secondary side are the pump trip according to the speed decrease aforementioned and an emergency supply (by a Diesel engine) of the primary and secondary pumps enabling their rotation at their back-up speed value. The transient effects are investigated first in case of failure of the reactor shutdown (unprotected transient) and then by considering the reactor scram.

\subsubsection{Unprotected transient}

In order to assess and to compare the natural behaviour of the core in case of LOOP depending on the PCS, calculations have been performed without scram in the case of the CFV core (Fig. 5). The core power (Fig. 5), governed by the reactivity feed-back is lower for the water PCS than for the gas PCS. This is due to a core inlet temperature that is higher in the case of the water PCS thus favoring the diagrid expansion. This temperature difference is explained by the difference of power removed by the ternary side depending on the PCS. In the case of the water PCS, the SG is dried out in approximately $30 \mathrm{~s}$ after the beginning of the transient, that is, with the same dynamics as the feed water decrease. After its dryout, the SG still removes some power during $900 \mathrm{~s}$ but only several Megawatts whereas the gas PCS removes about $100 \mathrm{MW}$ thanks to a substantial residual flow rate of about $250 \mathrm{~kg} / \mathrm{s}$ driven by natural convection induced by exchanges through the recuperator. 


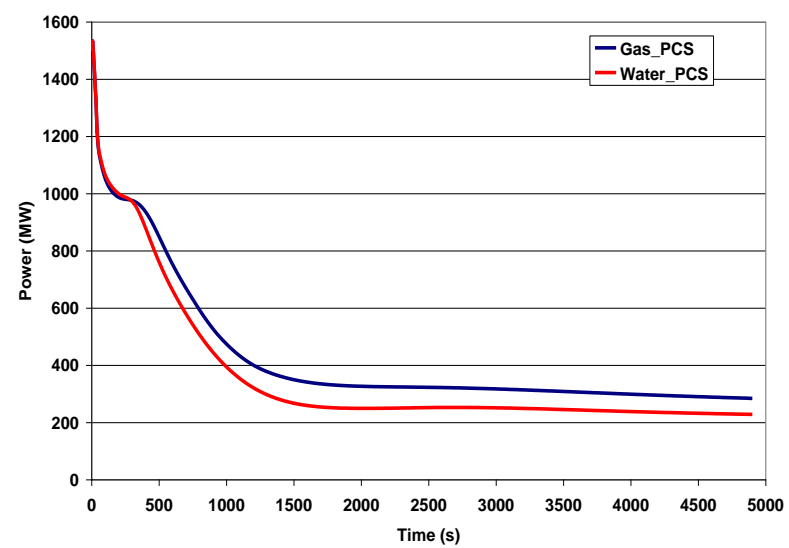

Fig. 5. Comparison of core power evolution in case of unprotected LOOP for gas and steam/water PCS

\subsubsection{Protected transient}

The actuation of the scram (Tab. 3) is triggered according to the reach of the threshold of the power to flow rate ratio for the water PCS (at $3.7 \mathrm{~s}$ ) whereas regarding the gas PCS, the threshold of the TM overspeed is reached $(1.3 \mathrm{~s})$ and induces the reactor scram and the opening of the TM by-pass line. The core power is the same for the 2 PCS since the transient occurs in a residual power regime. So it is not influenced by the thermalhydraulic parameters. For the gas PCS, as soon as the by-pass line is fully open (at $4 \mathrm{~s}$ ), the TM speed decreases up to zero in about $400 \mathrm{~s}$. Despite this absence of rotation of the turbomachinery, the ternary side remains featured by a gas flow rate ranging from about $200 \mathrm{~kg} / \mathrm{s}$ at the beginning of the transient down to $100 \mathrm{~kg} / \mathrm{s}$ at $5000 \mathrm{~s}$ thanks to exchanges through the recuperator that generates natural circulation. This behavior, already observed in the unprotected case, leads to more moderate heating of the secondary inventory and thus to a moderate primary inventory heating as well (Fig. 6). Even if the difference is about 20 or $30^{\circ} \mathrm{C}$, the impact on the vessel creep could be important for the long term transient. 


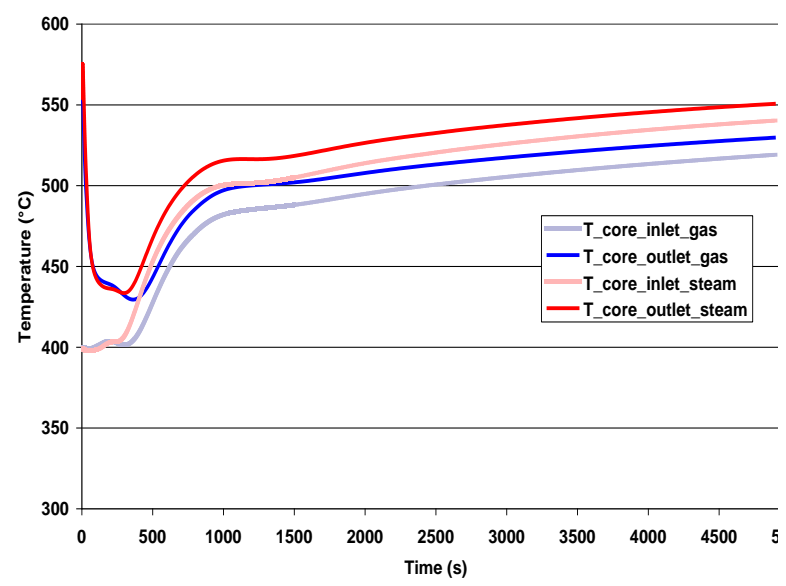

Fig. 6. Comparison of core temperature evolution in case of protected LOOP for gas PCS and for steam/water PCS

\subsubsection{Decay heat removal with the gas PCS}

During the LOOP transient, emergency electrical supply is available to deliver a back-up flow rate to the primary and secondary pumps as well as to the water-feeding system of the coolers. The aim of this subsection is to present the sensitivity of the system behavior to a back-up flow rate in the coolers ${ }^{4}$. Conversely to calculations presented in section 5.1.1, in this set of calculation, regulations actions presented in Table 4 are simulated in order to keep the ternary side under operation as long as possible as a temporary heat sink. Figure 7 shows that as soon as a back-up flow rate is available (even only $5 \%$ of the nominal flow rate), the core inlet temperature decreases of at least $150^{\circ} \mathrm{C}$ in one hour. It is interesting to observe that the minimum flow rate tested (5\%) is enough to keep the TM under operation. Therefore, the ternary flow rate and the cold source is enough to cool the core adequately, thus providing a substantial additional delay before switching the decay heat removal to the dedicated in-vessel loops. Moreover, the rotation of the TM enables to reduce the hot shock on the primary vessel by compensating the heating due to the loss of flow on the primary and secondary circuits $\left(+20^{\circ} \mathrm{C}\right.$ at the IHX outlet instead

\footnotetext{
${ }^{4}$ This study is only performed in order to assess the behavior of the system no matter what the decisions will be taken regarding the systems rescued: in particular, at that time, it is not foreseen to have an emergency electrical supply for the coolers.
} 
of $+75^{\circ} \mathrm{C}$ when the TM is stopped). Finally, the TM stops after approximately $1 \mathrm{~h}$ whatever the flow rate of the coolers.
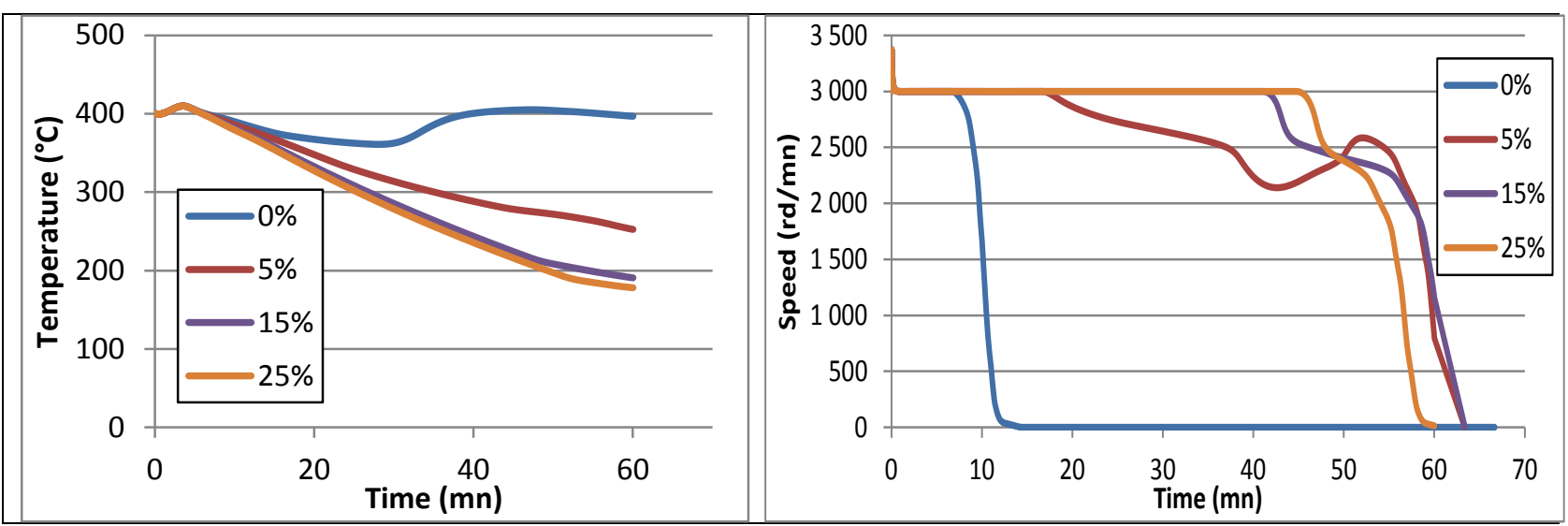

Fig 7. Core inlet temperature and turbomachine rotation speed for various back-up flow rates of the coolers (from 0 to $25 \%$ )

\subsection{Black-out}

This transient results from the total loss of electrical supply: there is no back-up flow rate delivered by means of emergency electrical supply and the water feeding of the coolers is unavailable as well. The reactor trip is actuated at the beginning of the transient. The pump run-down is governed by their inertia. The power balance between the core and the reactor circuits and the temperature evolution across the core and on the interface between the secondary and ternary circuits are presented on Figure 8. A cold shock affects all the circuits because of the heat extraction by the ternary circuit thanks to a substantial flow rate that remains in this circuit thanks to the TM operation and to the gas expansion in it (Fig. 6). This can be observed on Fig. 5 because the nitrogen temperature at the inlet of the SGHX decreases up to $300^{\circ} \mathrm{C}$ because only the decay heat is transferred to the PCS and yet, its flow rate remains very high as long as the TM is under rotation. 

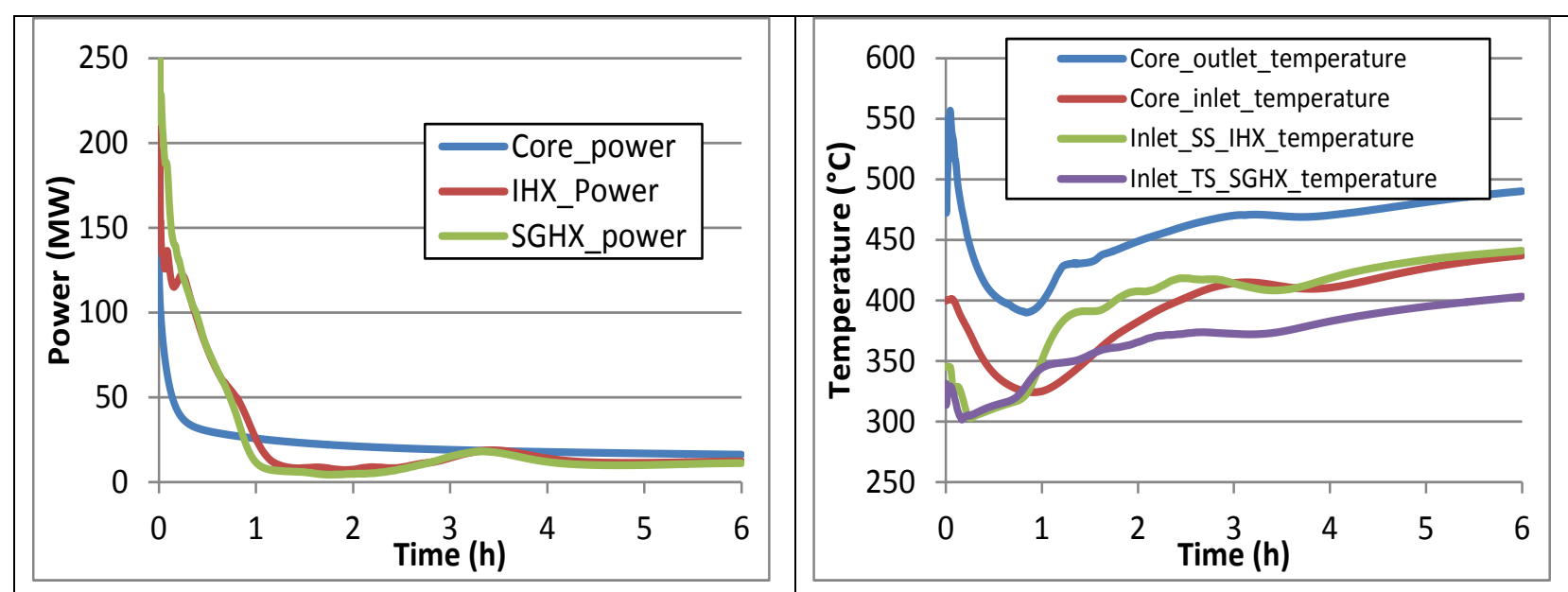

Fig. 8. Power balance and temperature evolutions during the black-out transient
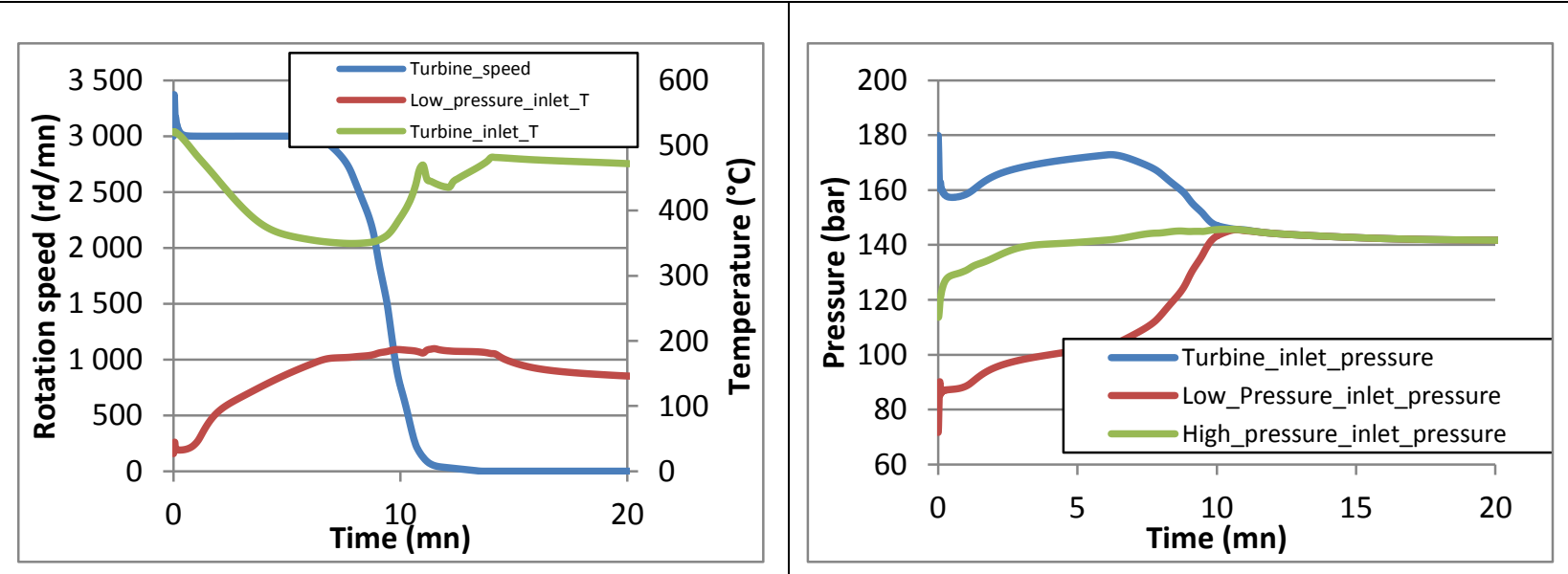

Fig. 9. Rotation speed, temperature and pressure evolution across the turbomachine

After 10 minutes, the balance between the heat transferred to the PCS from the core and the heat released by the coolers leads to the TM rundown (Fig. 9). As a consequence, at this time, the PCS pressure is balanced around 140 (Fig. 9) bars and the secondary and ternary side temperatures begin to increase. At $1 \mathrm{~h}$, a thermal and power balance is reached and the heat removed by the ternary side becomes lower than the decay heat and the primary sodium temperature begins to increase. Actually, even after the primary and secondary pumps shutdown and the TM rundown, natural circulation flows in each circuit drive the whole reactor cooling. However, this result should be to confirm considering the uncertainty on the natural circulation regime calculation (pressure head of the stopped pumps, performance maps of the TM and circuit elevation are not assessed adequately). Nevertheless, this result indicates that the heating rate of the whole system is very low and that thanks to the Brayton cycle and of the inertia of the reactor 
cooling circuits, the PCS enables the decay heat to be removed more than 6 hours without reaching the temperature level of the nominal state of the reactor.

\subsection{Spurious opening of by-pass valves}

Various flow paths are possible (Fig. 10) in order to by-pass the turbine and practically, a mix of gas taken in the cold leg (opening of by-pass2) and of gas taken in the hot leg (opening of by-pass1) is injected in the exhaust pipe of the turbine (opening of by-pass4). The transients calculated in this paper deal respectively with the spurious opening of the lines by-pass $1+$ by-pass4 (called BYP1) and of the spurious opening of the lines by-pass $2+$ by-pass4 (called BYP2). The spurious opening of the valves is realized in $3 \mathrm{~s}$. The line by-pass 4 is open before the transient and the lines by-pass 1 and by-pass 2 are respectively made of 2 pipes of $60 \mathrm{~cm}$ diameter and when the transient occurs, 1 over 2 lines are open. As observed on figure 11, the case "BYP2" leads to a fast rundown of the TM due to the cold temperature of the gas in the cold leg, the flow rate by-passing the turbine being higher than in the case "BYP1". As a result, the flow rate in the PCS is reduced faster in the case "BYP2" than in the case "BYP1" and the heating of the sodium at the core inlet occurs earlier (Fig. 11).

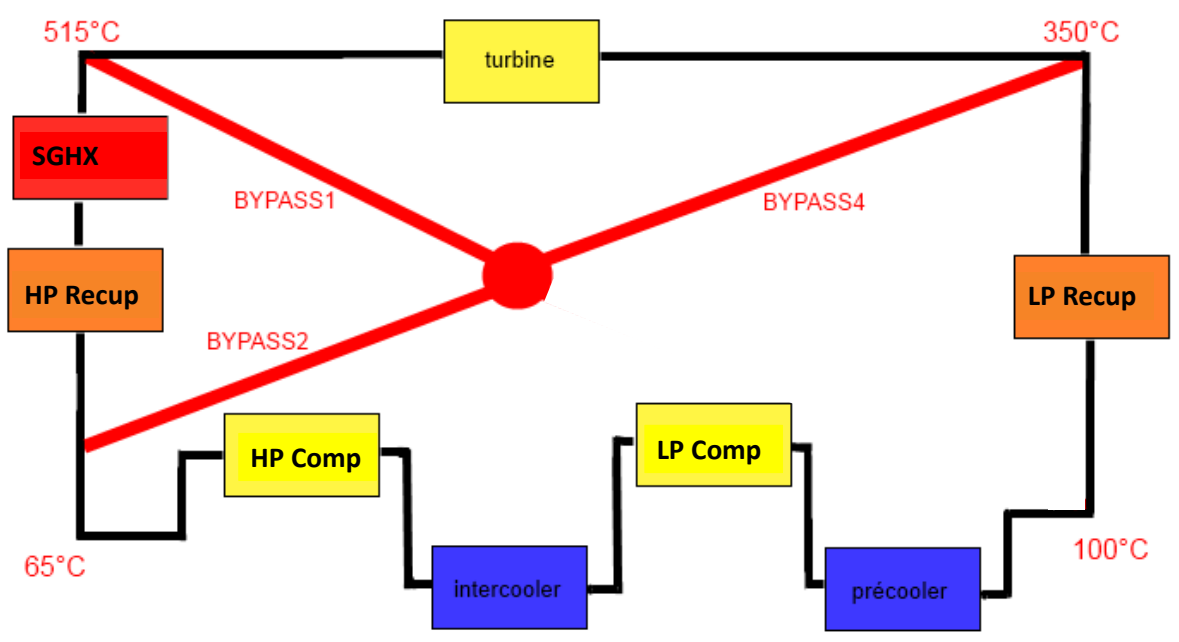

Fig. 10. Sketch of the by-pass line system in the PCS (HP comp and LP comp : high pressure and low pressure compressors; HP recup and LP recup: high pressure and low pressure recuperator sides; SGHX: sodium gas heat exchanger) 


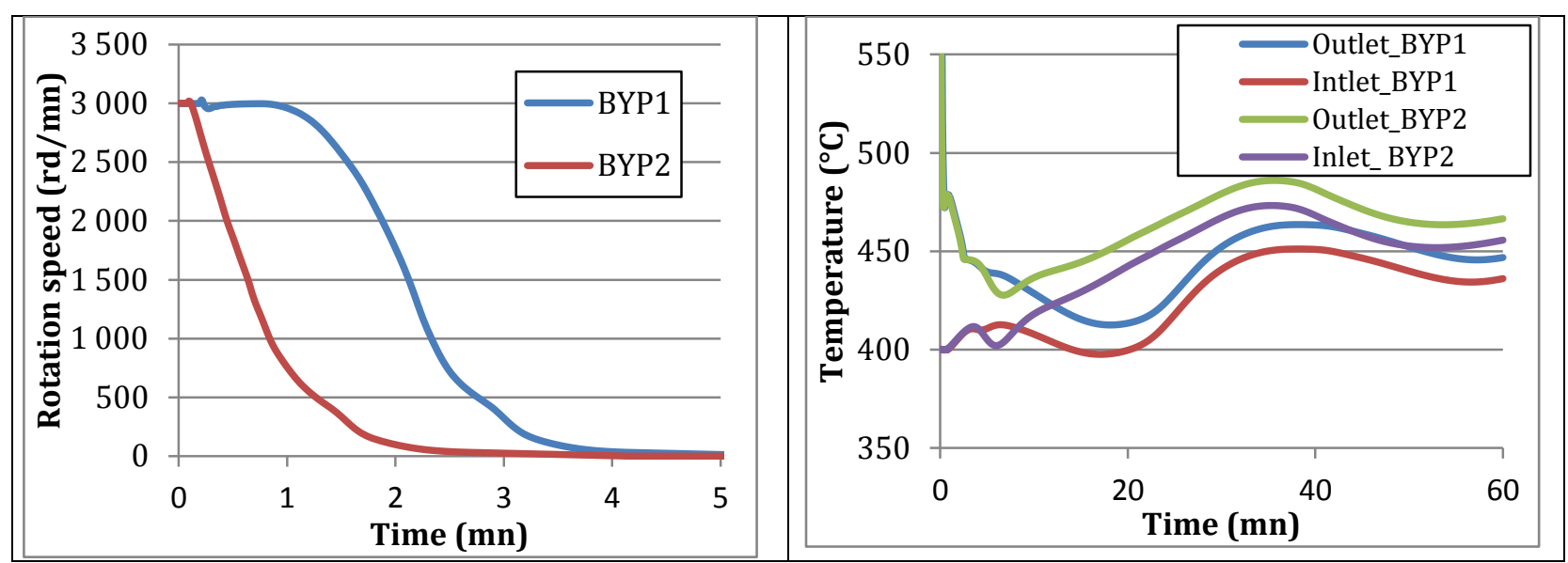

Fig. 11. TM rotation speed and temperature across the core for by-pass valve opening transients

The reference design option including 2 by-pass pipes for the parts of the circuit called BYPASS1 and BYPASS2 leads to an over-speed of the TM equal to $114 \%$ of its nominal speed. By keeping the same over-speed, the BYPASS1 and BYPASS2 lines have been sub-divided into smaller pipes (6 pipes of 25 cm diameter) in order to limit the transient impact of the opening of one single line. In the case "BYP2" the reactor trip threshold are not reached and thus, the reactor is not scrammed, even after a long time. The electrical power delivered to the alternator remains higher than the minimum value. Therefore, the alternator remains connected and the core power is extracted. However, in the case "BYP1", due a hotter gas intake in the recuperator, the core inlet temperature increases and reaches the trip level (Fig. 12) after 55 minutes. This exploratory calculation has shown that by designing more modular by-pass line, it is possible in the same time to limit adequately the turbine over-speed and to keep the reactor under operation. 

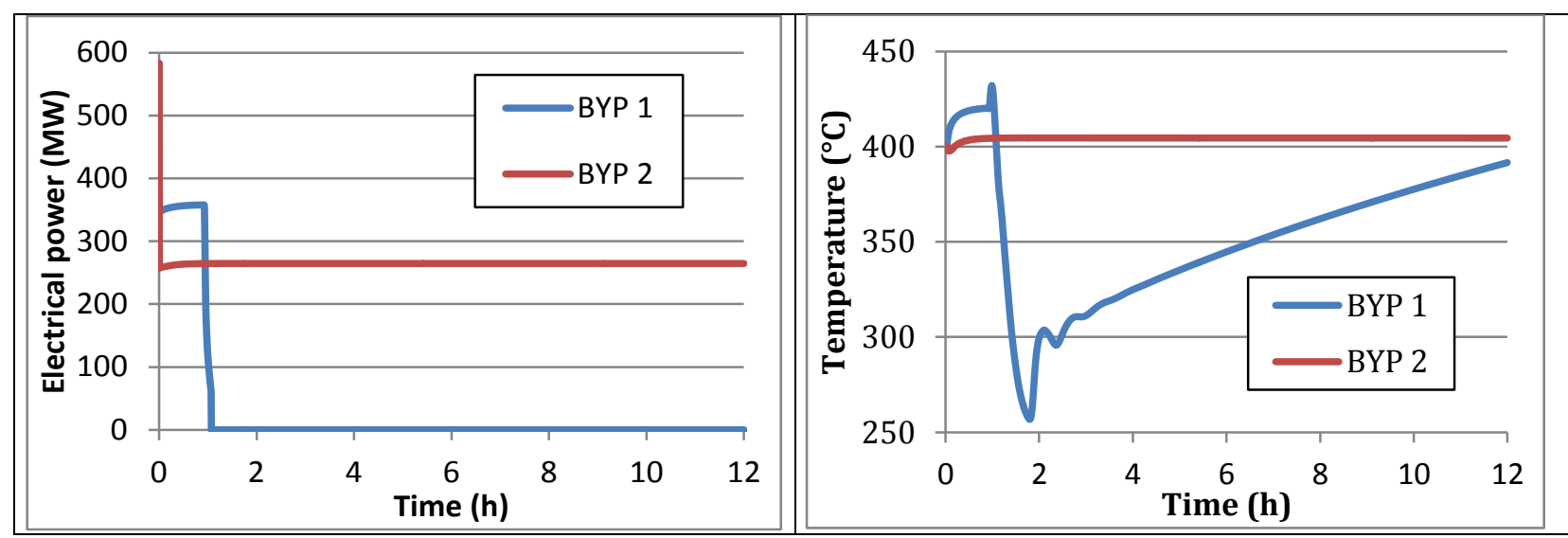

Fig. 12. Alternator electrical power and core inlet temperature for by-pass valve opening transients, impact of design improvement

\section{PCS depressurization transients}

These depressurization transients result from breaches in the PCS and are typical from pressurized gas circuits. Two break locations have been studied: upstream of the SGHX (labelled AM_SGHX on fig. 4) and downstream of the turbine (labelled AV_TURB on Fig. 4). Two diameters have been studied as well: 10 inches representing (in order of magnitude) the size of the piping on the main branches of the PCS and 40 inches representing the size of those main branches. The reactor trip signal and the operation of the reactor circuits are the same as indicated in section 4 except the cooler flow rate that is kept at its nominal value because the initiating event does not lead to the loss of the cooling circuits.

\subsection{0 inch diameter breach}

As observed on Figure 13 through the power delivered to the alternator, the TM is kept under rotation a longer time for the break located downstream of the turbine (AV_TURB) than for the case (AM_SGHX). This is due to the increase of the expansion ratio induced by the depressurization of the low pressure part of the PCS. As a result, the transient is compatible with the Brayton thermodynamic cycle for a long time and the low electrical power signal is reached later on (Figure 12). Since the TM keeps running, the compressors decrease the depressurization kinetics. The scram of the reactor occurs at about 8 min instead of $5 \mathrm{~min}$ (because of a too high core inlet temperature) because the balance between the power extracted 
by the PCS and the power released by the core leads later to the core inlet temperature threshold in the case AV_TURB than in the case AM_SGHX (Fig. 14). The primary temperature evolution indicates that in the case of a breach on the high pressure part of the circuit, the heating of the secondary and primary circuits resulting from the TM rundown occurring at $12 \mathrm{~min}$ limits the cold shock in the primary circuit. It induces a shift of about $150^{\circ} \mathrm{C}$ in the primary temperature evolution in the long term transient that is mainly governed by the primary and secondary circuits thermal inertia once the depressurization of the PCS is over (after 1 hour). Thus, depending on the breach location, the grace delay to start the in-vessel DHR systems can be shifted of more than 5 hours (Fig. 14).
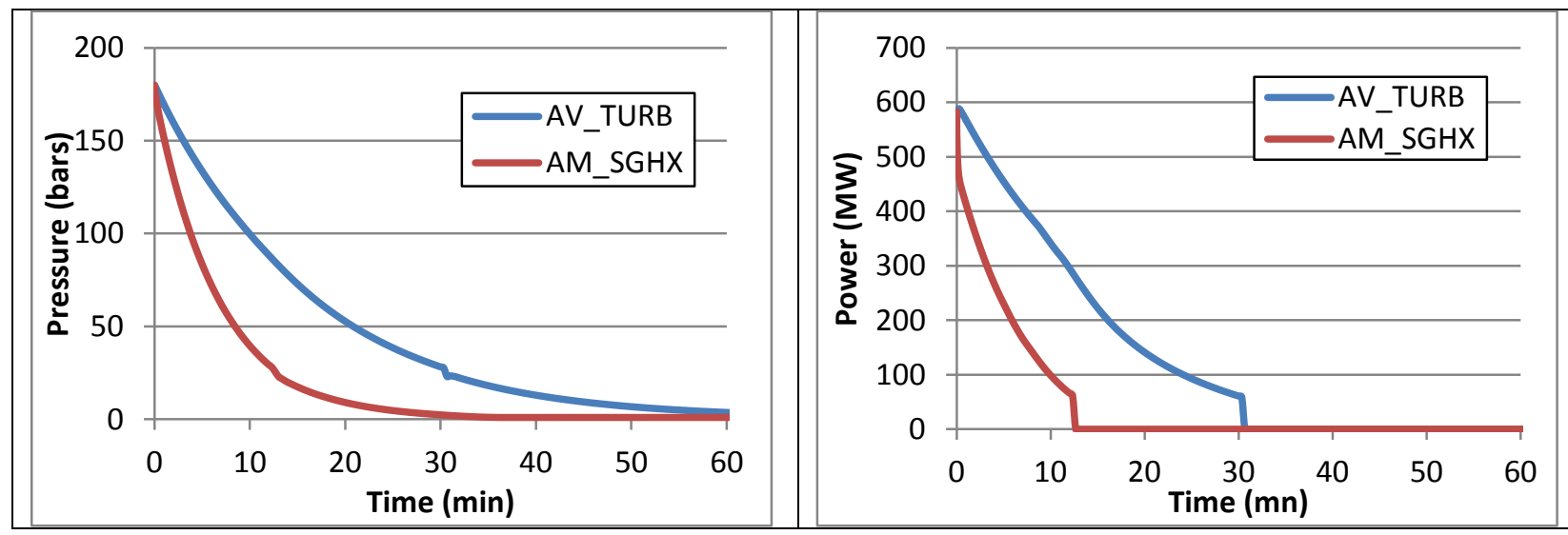

Fig. 13. PCS depressurization transient and electrical power transient for a 10 inch breach
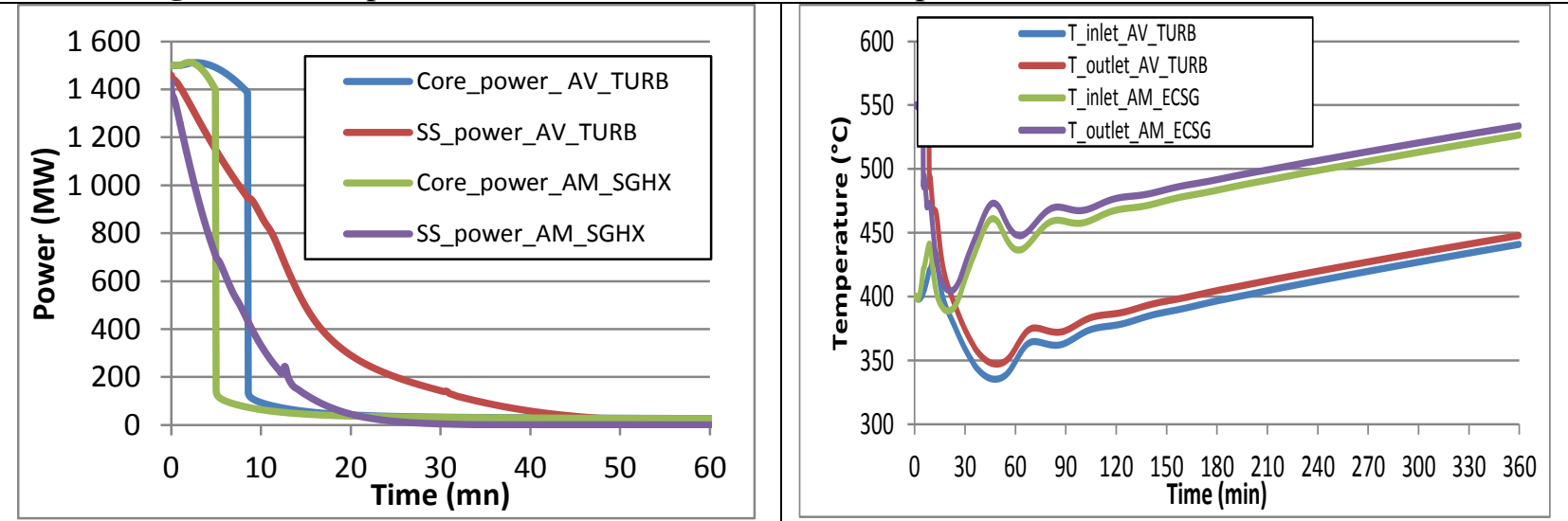

Fig. 14. Core power and extracted secondary power (SS_power), core inlet and outlet temperature (10 inch breach)

\subsection{0 inch diameter breach}

This size of breach is equivalent to the rupture of the largest pipe of the parallel modules of the PCS either upstream of the SGHX (case AM_SGHX) or downstream of the turbine (case AV_TURB). This break 
size leads to a very fast depressurization inducing a flow inversion in pipe portions downstream of the breach including the TM components. So, these results are only preliminary and will be checked with ALSTOM performance map when they will be included in the CATHARE2 input deck. However, the system behavior is consistent with that calculated for more little breaches but with a much faster dynamics. The reactor scram is reached in 6 tenth of seconds in the case AV_TURB because of an out of range electrical power delivered by the turbine (expansion rate and flow increase in the turbine, thus increasing the electrical power) and it is reached after $6 \mathrm{~s}$ in the case AM_SGHX because of a to low electrical power due to the same factors, but acting inversely. As long as the alternator is connected, the case AV_TURB leads to a cooling of the primary circuit but less pronounced than for the 10 inch breach because the ternary flow rate decreases fast due lack of gas inventory in the circuit. So, as far as very large breaches are concerned, the location of the breach has a lower impact on the transient evolution of the reactor (Fig. 15). Once the depressurization is over and once the cold shock is over, the heating rate of the primary circuit is the same for both breach locations.

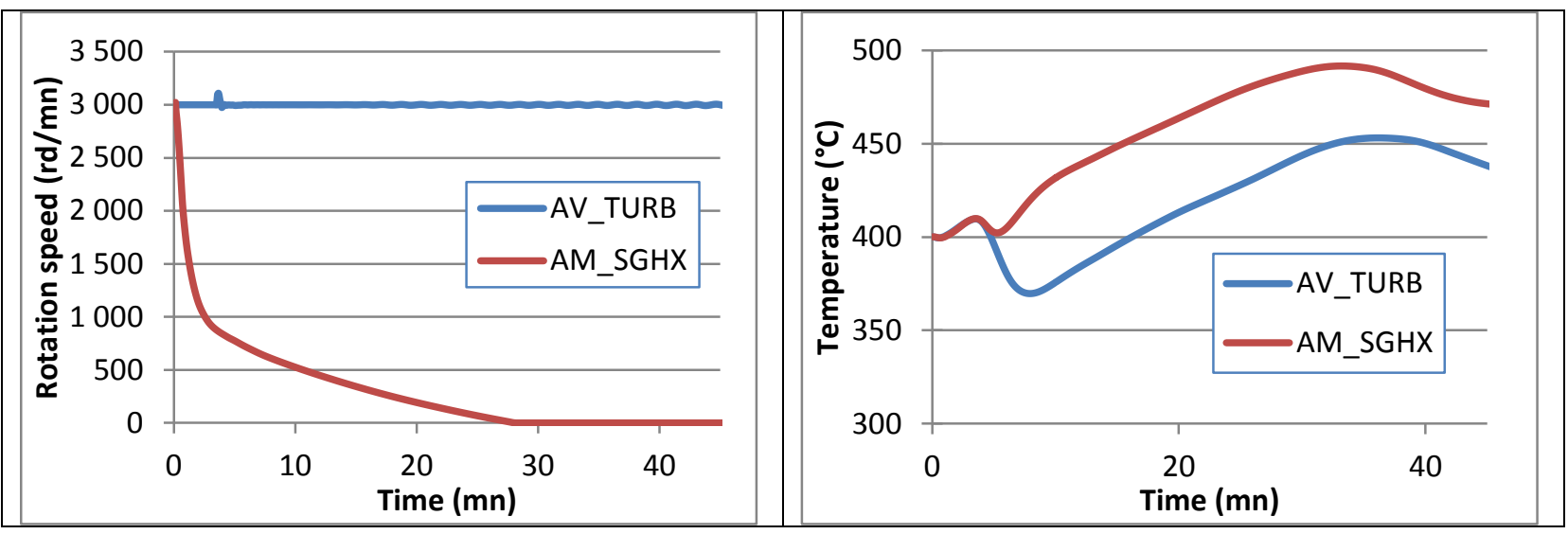

Fig. 15. TM rotation speed and core inlet temperature for a 40 inch breach

\section{Conclusions}

The comparison of both PCS studied for ASTRID during the pre-conceptual design phase of the project has shown that, in case of loss of site power, the transient behavior of the reactor is not very different between the water/steam PCS and the gas one. However, the cold plenum temperature calculated for gas 
PCS seems to be lower by about 20 at $30^{\circ} \mathrm{C}$ than that of the water/steam PCS. Typical transient resulting from typical initiating events of a gas PCS have been investigated. First, the overall reactor behavior when facing PCS transients does not exhibit any specific showstopper in terms of impact of the ternary circuit onto the primary and core temperature evolution compared to a water/steam PCS. Several lessons learnt from the calculations could be used for the reactor design and piloting if necessary in order to consolidate the safety design of the reactor or to relax operation constraints on dedicated DHR systems. Regarding the design, the increase of the number of TM by-pass lines allowing the decrease of the flow rate in each line would enable the reactor to withstand a spurious opening of a single by-pass line without exceeding the thresholds of the reactor trip protection system. Another interesting conclusion of the study is the capability of the PCS to remove the decay heat during several hours providing that the TM is kept under operation at the beginning of the transient. This capability is even enhanced by feeding the cold side of the PCS coolers with only 5\% of its nominal water flow rate. This could be done by a rescue of the feeding pumps at a low power level requiring only a small power supply from the emergency Diesel engines.

\section{Acknowledgment}

The authors would like to thank their colleagues of AREVA NP for their work on the CATHARE2 input deck, as well as, the sodium fast reactor R\&D project and the Gen IV program of the Nuclear Energy Division of CEA that have supported this work.

\section{References}

Bertrand F. et al., 2016. Comparison of the behaviour of two core designs for ASTRID in case of severe accidents. Nuclear Engineering and Design, Volume 297, February 2016, Pages 327-342.

Cachon L. et al., 2012. Innovative power conversion system for the French SFR prototype, ASTRID, proceedings of ICAPP, Chicago, USA, June 24-28, 2012.

Chenaud M.S. et al., 2013. Status of ASTRID core design studies at the end of predesign phase 1", Nuclear Engineering and Technology, Vol. 45, N 6. 
Geffraye G. et al., 2009. CATHARE 2 V2.5_2: a Single Version for Various Applications, The 13th International Topical Meeting on Nuclear Reactor Thermalhydraulics (NURETH-13), Kanazawa City, Ishikawa Prefecture, Japan, September 27-October 2, 2009.

Laffont G. et al., 2013. ASTRID power conversion system: assessment on steam and gas options, proceedings of FR13, Paris, France, 4-7 March 2013; Paper CN-199-262.

Le Coz P. et al., 2013. The ASTRID Project: status and future prospects, proceedings of FR13, Paris France 4-7 March 2013; Paper CN 199-261.

Lemasson D., Bertrand F., 2014. Simulation with SAS-SFR of a ULOF transient on ASTRID-like core and analysis of molten clad relocation dynamics in heterogeneous subassemblies with SAS-SFR, Proceedings of ICAPP, Charlotte, USA, April 6-9, 2014.

Sciora P., 2011. Low void effect core design applied on 2400 MWth SFR reactor, proceedings of ICAPP, Nice, France, May 2-6, 2011.

Widlund et al., 2005. Overview of Gas Cooled Reactor applications with CATHARE, The 11th International Topical Meeting on Nuclear Reactor Thermalhydraulics (NURETH-11), Popes Palace Conference Center, Avignon, France, October 2-6, 2005.

\section{Nomenclature}

$\begin{array}{ll}\mathrm{P} & \text { Power }(\mathrm{W}) \\ \mathrm{P}_{\text {elec }} & \text { Electrical power }(\mathrm{W}) \\ \mathrm{Q} & \text { Flow rate }(\mathrm{kg} / \mathrm{s}) \\ \mathrm{T} & \text { Temperature }\left(\mathrm{K} \text { or }{ }^{\circ} \mathrm{C}\right) \\ \mathrm{T}_{\mathrm{ci}} & \text { Core inlet temperature }\left(\mathrm{K} \text { or }{ }^{\circ} \mathrm{C}\right) \\ \mathrm{T}_{\mathrm{co}} & \text { Core outlet temperature }\left(\mathrm{K} \text { or }{ }^{\circ} \mathrm{C}\right) \\ \mathrm{t} & \text { Time }(\mathrm{s}) \\ \omega & \text { Rotational speed }(\mathrm{rnd} / \mathrm{mn})\end{array}$

Subscripts

$\mathrm{N} \quad$ Related to the nominal operating point of the reactor

\section{Glossary}

DHR decay heat removal GFR gas-cooled fast reactor 


$\begin{array}{ll}\text { HC } & \text { hexcan } \\ \text { HP } & \text { high pressure } \\ \text { HTR } & \text { high temperature reactor } \\ \text { IE } & \text { Initiating event } \\ \text { (I)HX } & \text { (intermediate) heat exchanger } \\ \text { LOOP } & \text { Loss of off-site power } \\ \text { LP } & \text { low pressure } \\ \text { NSS } & \text { Nitrogen supply service system } \\ \text { PCS } & \text { power conversion system } \\ \text { SA } & \text { fuel sub-assembly } \\ \text { SG } & \text { Steam generator } \\ \text { SGHX } & \text { sodium gas heat exchanger } \\ \text { SS } & \text { secondary side } \\ \text { TM } & \text { turbomachinery } \\ \text { TS } & \text { ternary side }\end{array}$

